\title{
POTENSI KONSEP MATEMATIKA DALAM PEMILIHAN DUTA PERTANIAN KALIMANTAN BARAT
}

\author{
Constanius Putra Bepa, Dede Suratman, Bistari \\ Program Studi Pendidikan Matematika FKIP Universitas Tanjungpura Pontianak \\ Email: cputrabepa619@gmail.com
}

\begin{abstract}
Mathematics is a science that is always used by humans throughout their lives. In the selection of the West Kalimantan Agricultural Ambassador, we will look for the concept of activities related to mathematics concepts and implementation with school mathematics. Using a descriptive method, because the purpose of this study is to describe the mathematical concepts contained in the selection of the West Kalimantan Agricultural Ambassador. Researchers conducted interviews with 4 sources. It aims to obtain data related to the selection of the West Kalimantan Agricultural Ambassador. From the results of the interview, the researcher digs up information about the preparation, implementation and closing activities. There is a mathematical concept in the third, the aspect of selecting the West Kalimantan Agricultural Ambassador.
\end{abstract}

Keywords: Mathematics, West Kalimantan Agricultural Ambassador,

\section{Pendahuluan}

Matematika adalah ilmu yang selalu digunakan oleh manusia sepanjang hidupnya. Menurut Profesor Iant Pritcheet yang meneliti anak-anak berusia 15 tahun di Jakarta ternyata anak-anak di Jakarta ketinggalan 128 tahun dengan negara-negara lainnya dibidang matematic, science, reading (Umiyatun et al., 2015).

Matematika menjadi salah satu bidang dimana anak-anak memiliki kemampuan serta kemauan yang rendah. Padahal matematika selalu kita jumpai dalam kehidupan sehari-hari. Selain di Sekolah, matematika juga dapat kita jumpai dalam pemilihan Duta Pertanian Kalimantan Barat (Yusuf \& Basuni, 2017).

Kalimantan Barat menjadi daerah pertama yang mengadakan pemilihan Duta Pertanian Kalimantan Barat. Kepala Dinas Pertanian Tanaman Pangan dan Hortikultura Provinsi Kalimantan Barat, Bapak Heronimus Hero mengungkapkan Duta Pertanian dibentuk dengan tujuan menyebarluaskan edukasi serta informasi terkait pertanian, Duta Pertanian diharapkan dapat menjadi juru kampanye, membantu Pemerintah menyebarluaskan program, prosek-prospek pertanian, mengajak masyarakat untuk mencintai dan beraktivitas di dunia pertanian (Jamiah, 2020); (Pratikna et al., 2020).

Pada malam penobatan pemilihan Duta Pertanian Kalimantan Barat, yang diikuti oleh 30 besar peserta yang terdiri dari 15 peserta putra dan 15 peserta putri kemudian dilakukan babak penyisihandari 15 besar menjadi 5 besar yang berhak mengikuti babak selanjutnya untuk menyampaikan visi dan misi lalu dikerucutkan menjadi 3 besar yang akan diberikan pertanyaan oleh dewan juri. Pada babak 3 besar (terdiri dari 3 putra dan 3 putri) masing-masing peserta mengambil secara acak gulungan kertas yang terdapat di dalam ball. Di dalam ball tersebut terdapat 6 gulungan kertas, 2 kertas bertuliskan 1 nama dewan juri.

Berdasarkan fakta dan uraian diatas, terlihat adanya hubungan antara potensi konsep matematika dengan pemilihan Duta Pertanian Kalimantan Barat. Maka, peneliti tertarik 
Vol 2 No 1 Juli 2021

Jurnal AlphaEuclidEdu

Received:07/12/2020; Resived:04/03/2021; Accepted:03/07/2021

untuk mengkaji lebih dalam terkait hubungan potensi konsep matematika dalam pemilihan Duta Pertanian Kalimantan Barat.

\section{METODE PENELITIAN}

Pada penelitian ini, Peneliti menggunakan metode deskriptif, karena bertujuan untuk menjelaskan konsep matematika yang terdapat pada pemilihan Duta Pertanian Kalimantan Barat. Melalui Penelitian deskriptif, Peneliti berusaha untuk mendeskripsikan kejadian serta peristiwa yang menjadi fokus perhatian tanpa memberikan perlakukan khusus terhadap peristiwa tersebut (Noor,2017:35).

Subjek dalam penelitian ini meliputi dewan juri Duta Pertanian Kalimantan Barat terdiri dari 3 (tiga) orang narasumber yang dipilih berdasarkan peran serta dalam kegiatan tersebut.Bapak Heronimus Hero (Narasumber 1), Ibu Patricia (Narasumber 2), Bapak Supriyadi (Narasumber 3), ketiga narasumber tersebut dipilih berdasarkan peran penting dalam pemilihan Duta Pertanian Kalimantan Barat serta 1(satu) orang narasumber yaitu seorang Guru bernama Rianto. Narasumber dipilih untuk menghubungkan implementasi etnomatematika dalam pemilihan Duta Pertanian Kalimantan Barat kedalam pembelajaran matematika.

Objek Penelitian ini adalah konsep matematika dalam pemilihan Duta Pertanian Kalimantan Barat yang berpotensi untuk diangkat dalam pembelajaran matematika. Ada 3 tahapan dalam prosedur penelitian meliputi: tahap persiapan, tahap pelaksanaan dan tahap pelaporan.

Teknik pengumpulan data merupakan suatu proses atau pengadaan untuk keperluan penelitian dimana data yang terkumpul adalah untuk menguji hipotesis yang telah dirumuskan (Rukayat, 2018:20). Teknik dan alat pengumpulan data yang digunakan dalam penelitian ini adalah sebagai berikut: 1). Observasi. Metode Observasi merupakan upaya mengamati dan mendokumentasi hal-hal yang terjadi selama tindakan berlangsung (Suryana, 2010). Dalam penelitian ini peneliti melakukan pengumpulan data secara terus terang kepada sumber data bahwa peneliti sedang melakukan penelitian. Tetapi dalam keadaan tertentu, peneliti tidak terus terang atau tersamarkan dalam observasi dikarenakan untuk menghindari data yang dicari merupakan data yang dirahasiakan. Observasi dilakukan untuk mengamati unsur matematika dalam pemilihan Duta Pertanian Kalimantan Barat. 2). Wawancara. Wawancara adalah pertemuan dua orang untuk bertukar informasi dan ide melalui tanya-jawab, sehingga dapat dikonstruksi makna dalam suatu topik tertentu. Wawancara dilakukan untuk mengetahui secara mendalam mengenai pemilihan Duta Pertanian Kalimantan Barat. Pedoman wawancara yang dibuat agar dalam pelaksanaan peneliti mendapat informasi yang mendalam mengenai pemilihan tersebut. Pedoman wawancara merupakan alat bantu dalam pengambilan data di lapangan. 3). Dokumentasi. Dokumentasi yaitu mencari data mengenai hal-hal atau variabel yang berupa catatan, transkip, buku, surat kabar, majalah, agenda dan sebagainya (Winarno, 2013:154).

Teknik analisis data dalam penelitian ini adalah analisis data model Miles dan Huberman. Miles dan Huberman dalam Sugiyono (2017:133) mengemukakan bahwa aktivitas dalam analisis data kualitatif dilakukan secara interaktif dan berlangsung secara terus menerus sampai tuntas, sehingga datanya sudah jenuh. Langkah-langkah analisis data menurut Miles dan Huberman yaitu: a). Data Condensation (Kondensasi Data), b). Data Display (Penyajian Data), c). Conclusion Drawiing/Verification. 


\section{HASIL PENELITIAN DAN PEMBAHASAN}

\section{Hasil}

\section{A. Hasil Wawancara Juri}

1. Aspek Persiapan
$P \quad$ : "Apa saja atribut yang digunakan dalam Pemilihan Duta Pertanian Kalimantan Barat?"
NS1 : "Pakaian, selempang, mahkota, papan nama, piala, caping."
NS2 : "Selempang, nomor undian, alat tulis."
NS3 : "Selempang, tongkat, mahkota."
$P \quad: \quad$ :Bentuk alat yang digunakan seperti apa?"
NS1 : "persegi (papan nama), persegi panjang (selempang), caping (bulat)."
NS2 : "persegi panjang (selempang), persegi."
NS3 : "persegi panjang (selempang,bahan kain), tabung (tongkat)."
$P \quad$ : "Bagaimana cara peserta Duta Pertanian Kalimantan Barat berkumpul ketika akan memulai kegiatan?"
NS1 : "koordinasi, sesuai jadwal, berkelompok."
NS2 : "sesuai jadwal yang telah ditentukan oleh panitia."
NS3 : "sesuai jadwal yang telah diberikanoleh panitia."
$P \quad:$ "Apakah ada aturan tertentu ketika akan berkumpul?"
NS1 : "sesuai gender, berpasangan dan sesuai bakat."
NS2 : "15 menit sebelum kegiatan harus sudah berkumpul."
NS3 : "Ada, dapat berupa aturan minimal dan maksimal jumlah orang dalam berdiskusi maupun dalam mengajukan pertanyaan."

Berdasarkan hasil dari wawancara dalam aspek persiapan diperoleh bahwa didalam aspek persiapan terdapat beberapa konsep matematika seperti bangun datar (persegi panjang, lingkaran) dan himpunan.

\section{Aspek Pelaksanaan}

$P \quad: \quad$ "Bagaimana bentuk panggung pemilihan duta pertanian kalimantan barat?"

NS1 : "berukuran $8 \times 15$ m berbentuk persegi panjang."

NS2 : "melebar (persegi panjang)."

NS3 : "segi empat (persegi panjang)."

$P \quad$ : “Apakah kegiatan Duta Pertanian Kalimantan Barat dilakukan secara individu atau berpasangan?"

NS1 : "berpasangan."

NS2 : "berpasangan/berkelompok."

NS3 : "individu dan berpasangan."

$P \quad$ : "Bagaimana cara membagi peserta kedalam sebuah kelompok?"

NS1 : "sesuai dengan kegiatan."

NS2 : "disesuaikan dengan keinginan narasumber misalnya narasumber menginginkan 5 kelompok maka akan dibagi jumlah peserta dibagi 5."

NS3 : "Biasanya berupa undian, diacak berdasarkan nomor undian." 
Vol 2 No 1 Juli 2021

Jurnal AlphaEuclidEdu

Received:07/12/2020; Resived:04/03/2021; Accepted:03/07/2021

Berdasarkan Aspek Pelaksanaan diperoleh beberapa konsep matematika seperti persegi panjang, himpunan dan konsep peluang.

3. Aspek Penutupan

$P \quad$ : "Bagaimana cara menentukan posisi peserta diatas panggung?"

NS1 : "koreografi."

NS2 : " disesuaikan dengan koreo dan pasangan. “

NS3 : "Diatur oleh koreografer."

$P \quad$ : "Bagaimana cara menentukan posisi disetiap babak sehingga didapatkan pemenang dari Duta Pertanian Kalimantan Barat?'

NS1 : " 30 besar-10 besar-6 besar- pemenang."

NS2 : "sesuai koreografi dari panitia."

NS3 : "Untuk mekanisme penentuan posisi sesuai koreo dari panitia."

$P \quad$ : "Apa saja hadiah yang diberikan kepada para pemenang?"

NS1 : "uang kas, piala, mahkota, selempang, piagam."

NS2 : "uang tunai, piagam."

NS3 : "uang tunai, piagam."

$P \quad:$ "Apa saja bentuk matematika yang terdapat pada hadiah tersebut?”

NS1 : “persegi panjang, lingkaran.”

NS2 : "persegi panjang."

NS3 : "Berupa angka, misalnya nominal besaran uang."

Berdasarkan hasil wawancara diperoleh bahwa didalam aspek penutupan terdapat beberapa konsep matematika seperti konsep peluang, persegi panjang, lingkaran, pola bilangan, bilangan dan himpunan.

\section{B. Hasil Wawancara Guru}

\section{Aspek Persiapan}

$P \quad$ : "Mengenai atribut yang digunakan dalam Pemilihan Duta Pertanian Kalimantan Barat kira-kira materi apa yang cocok dalam pembelajaran matematika di sekolah?"

G : "konsep matematika pada bangun datar."

$P \quad: \quad$ "Mengenai kegiatan berkumpul yang dilakukan oleh peserta dalam Pemilihan Duta Pertanian Kalimantan Barat kira-kira materi apa yang cocok dalam pembelajaran di sekolah?"

G : "Konsep matematika himpunan."

Berdasarkan hasil dari wawancara dalam aspek persiapan terdapat konsep matematika bangun datar dan himpunan.

\section{Aspek Pelaksanaan}

$P \quad$ : "Mengenai panggung yang digunakan dalam pemilihan Duta Pertanian Kalimantan Barat apa kira-kira materi yang cocok dalam pembelajaran matematika di sekolah?"

G : "konsep matematika pada bangun datar." 
Vol 2 No 1 Juli 2021

Jurnal AlphaEuclidEdu

Received:07/12/2020; Resived:04/03/2021; Accepted:03/07/2021

$P \quad$ : “ Mengenai berbagai kegiatan yang dilakukan dalam Pemilihan Duta

Pertanian Kalimantan Barat apa kira-kira materi yang cocok dalam pembelajaran matematika di sekolah?"

G : : Konsep matematika himpunan."

$P \quad: \quad$ :Mengenai pembagian peserta kedalam sebuah kelompok apa kira-kira materi yang cocok dalam pembelajaran matematika di sekolah?"

G : :Konsep Matematika Himpunan dan Peluang."

Berdasarkan hasil dari wawancara dalam aspek penutupan terdapat konsep matematika bangun datar, himpunan dan peluang.

\section{Aspek Penutupan}

$P \quad:$ " Mengenai penentuan posisi dalam Pemilihan Duta Pertanian Kalimantan Barat kira-kira materi apa yang cocok dalam pembelajaran matematika di sekolah?"

G : " konsep matematika himpunan, pola dan peluang."

$P \quad:$ " Mengenai hadiah dalam Pemilihan Duta Pertanian Kalimantan

Barat kira-kira materi apa yang cocok dalam pembelajaran matematika di sekolah?"

G : :"konsep matematika pada bangun datar dan bilangan."

Berdasarkan hasil dari wawancara dalam aspek penutupan terdapat konsep matematika pola, peluang, bangun datar dan bilangan.

\section{Pembahasan}

Penelitian ini bertujuan untuk mendeskripsikan konsep-konsep matematika yang terdapat pada pemilihan Duta Pertanian Kalimantan Barat. Pada tanggal 25-28 september 2020 peneliti melakukan wawancara kepada 4 narasumber. Hal ini bertujuan untuk mendapatkan data yang berkaitan dengan pemilihan Duta Pertanian Kalimantan Barat. Dari hasil wawancara peneliti menggali informasi mengenai aktivitas pada persiapan, pelaksanaan serta pentupan dalam pemilihan Duta Pertanian Kalimantan Barat.

Dari data yang dapat dilakukan reduksi untuk memperoleh aktivitas pemilihan Duta Pertanian Kalimantan Barat mengandung Konsep Matematika. Hal ini sesuai pernyataan oleh Hammond (Septiadi, 2017:5); (Afrilianto, 2017) bahwa setiap budaya atau kegiatan memiliki perhitungan, penyusunan, dan unsur matematika lainnya yang menyiratkan sesuatu mendasar dan kuat tentang dasar-dasar matematika. Selanjutnya peneliti mengidentifikasi konsep matematika apa saja yang terdapat dalam pemilihan Duta Pertanian Kalimantan Barat untuk menjawab rumusan masalah penelitian (Fitriawan et al., 2021); (Yusuf \& Basuni, 2017).

Data disajikan dalam uraian: 1). Aspek Persiapan pada Pemilihan Duta Pertanian Kalimantan Barat. Dalam aktivitas persiapan pemilihan Duta Pertanian kalimantan Barat ada beberapa kegiatan dilakukan yaitu menggunakan atribut peserta serta mengadakan perkumpulan awal. Berdasarkan kriteria tertentu termuat beberapa konsep matematika seperti himpuan, logika, persegi, persegi panjang, lingkaran, tabung. Konsep himpunan muncul ketika panitia melakukan pengelompokan pada saat berkumpul dan konsep bangun datar serta bangun ruang terdapat pada atribut yang digunakan para peserta Duta Pertanian Kalimantan Barat 2). Aspek Pelaksanaan pada Pemilihan Duta Pertanian Kalimantan Barat. Dalam aktivitas pelaksanaan pemilihan Duta Pertanian Kalimantan Barat ada beberapa kegiatan yang dilakukan yaitu penentuan posisi diatas panggung, bentuk panggung serta berbagai kegiatan yang dilakukan. Berdasarkan kriteria tertentu termuat konsep matematika seperti persegi panjang, konsep peluang dan konsep sistematika. 3). Aspek Penutupan pada pemilihan Duta Pertanian 
Vol 2 No 1 Juli 2021

Jurnal AlphaEuclidEdu

Received:07/12/2020; Resived:04/03/2021; Accepted:03/07/2021

Kalimantan Barat. Dalam aktivitas penutupan pemilihan Duta Pertanian Kalimantan Barat ada beberapa kegiatan yang dilakukan seperti melakukan penentuan posisi disetiap babak pada saat malam puncak, penentuan pemenang serta hadiah yang diberikan kepada para pemenang. Berdasarkan kriteria tertentu terdapat beberapa konsep matematika seperti konsep peluang, persegi panjang, persegi, lingkaran dan bilangan.4). Implementasi konsep matematika yang terdapat pada pemilihan Duta Pertanian Kalimantan Barat. Terhadap pengajaran matematika di Sekolah terdapat hubungan antara matematika dan pemilihan Duta Pertanian Kalimantan Barat yaitu pada materi bangun datar kelas 5, materi himpunan kelas 7, materi bilangan kelas 7, materi pola bilangan kelas 8 dan materi peluang kelas 8 .

\section{SIMPULAN DAN SARAN}

Berdasarkan hasil penelitian dan pembahasan diperoleh kesimpulan sebagai berikut. Simpulan

Berdasarkan hasil analisis dan pembahasan yang telah dipaparkan didapatkan kesimpulan bahwa Berdasarkan hasil penelitian yang telah dipaparkan, maka didapatkan kesimpulan sebagai berikut

1.Aspek persiapan pada Pemilihan Duta Pertanian Kalimantan Barat terdapat beberapa konsep matematika seperti himpunan, persegi, persegi panjang, lingkaran, tabung.

2.Aspek pelaksanaan pada Pemilihan Duta Pertanian Kalimantan Barat terdapat beberapa konsep matematika seperti persegi panjang, konsep peluang (probability), konsep himpunan.

3.Aspek penutupan pada Pemilihan Duta Pertanian Kalimantan Baat terdapat beberapa konsep matematika seperti konsep peluang, persegi panjang, persegi, lingkaran, bilangan.

4.Implementasi konsep matematika yang terdapat pada pemilihan Duta Pertanian Kalimantan Barat terhadap pengajaran matematika di sekolah yaitu materi bangun datar kelas 5 , materi himpunan kelas 7, materi bilangan kelas 7, materi pola bilangan kelas 8 dan materi peluang kelas 8 .

\section{Saran}

Berdasarkan penjelasan di atas, penelitian ini dapat dijadikan acuan bagi pendidik agar dapat memanfaatkan sesuatu yang ada disekitar sekolah untuk mendukung materi yang diajarkan dan dapat menghubungkan antara kegiatan sehari-hari atau sebuah kegiatan dengan konsep matematika.

\section{Referensi}

Afrilianto, M. (2017). Proses Berpikir Siswa dalam Menyelesaikan Soal Cerita pada Materi Spltv di SMA. Jurnal Pendidikan Dan Pembelajaran Untan, 6(11).

Fitriawan, D., Siregar, N., Pasaribu, R. L., \& Tanjungpura, U. (2021). Problematika dalam menilai sikap peserta didik pada pembelajaran daring. 2019-2022.

Jamiah, Y. (2020). Penguatan Karakter Siswa Perbatasan Melalui Internalisasi Kearifan Lokal Dalam $\begin{array}{lllll}\text { Pembelajaran } \quad \text { Matematika. Jurnal AlphaEuclidEdu, } & \text { 1(2), }\end{array}$ https://doi.org/10.26418/ja.v1i2.43306

Miles, M.B., Huberman, A.M. \& Saldana, Jhonny.(2014). Qualitative Data Analysis. (Edisi ke-4). The United States Of America: SAGE Publications.

Noor, Kania.(2018). Alat Peraga Untuk Memahami konsep Pecahan. Jurnal Pendidikan Matematika. Bandung.

Pratikna, D. S., Sugiatno, S., \& Hartoyo, A. (2020). Pengembangan Instrumen Eksplorasi Konsep Geometri Berstruktur Dari Teori Van Hiele Berbantuan Software Geogebra. Jurnal AlphaEuclidEdu, 1(2), 121. https://doi.org/10.26418/ja.v1i2.42881

Rukayat, Ajat.(2018).Pendekatan Penelitian Kualitatif. Yogyakarta:Deepublish.

Septiadi, Irawan.(2017).Potensi Adat Istiadat Robo-robo Pada Etnis Melayu Mempawah Untuk Pembelajaran Matemtika Sekolah. Skripsi. Pontianak:FKIP UNTAN. 
Vol 2 No 1 Juli 2021

Jurnal AlphaEuclidEdu

Received:07/12/2020; Resived:04/03/2021; Accepted:03/07/2021

Sugiyono. (2017). Metode Penelitian Kualitatif. (Cetakan Ke-3). Bandung: Alfabeta.

Suryana.(2010).Metodologi Penelitian: Model Praktis Penelitian Kuantitatif dan Kualitatif. Bandung: Universitas Pendidikan Indonesia.

Umiyatun, N., Hartoyo, A., \& Suratman, D. (2015). Pengaruh pembelajaran berbantuan. 3(2), 81-89.

Yusuf, \& Basuni, B. (2017). Konsep Dan Indikator Pembelajaran Efektif. In Jurnal Kajian Pembelajaran dan Keilmuan (Vol. 1, Issue 2, pp. 13-20). 